\title{
COMMUNICABLE DISEASES REPORT, NSW, FOR DECEMBER 2003 AND JANUARY 2004
}

\section{NEW WEB PAGE FOR INFECTIOUS DISEASES}

The NSW Department of Health now provides a new link to infectious diseases information on its website at www.health.nsw.gov.au under Quick Links. This new page offers updates on public health activities related to communicable disease control in NSW, as well as diseasespecific fact sheets and epidemiological reviews.

\section{TRENDS}

Reports of communicable disease in NSW received through to the end of January 2004 are summarised in Tables 4 and 5 and Figure 1. These data indicate that the incidence of meningococcal disease and pertussis declined through summer. The number of cases of gonorrhoea declined slowly but steadily throughout 2003 .

The number of cases of cryptosporidiosis has increased, especially in the Mid North Coast and Greater Murray Area Health Services. Cryptosporidiosis is a disease characterised by watery diarrhoea, which can last for several days and is caused by ingestion of the waterborne chlorine-resistant parasite Cryptosporidium. While no links among patients have been identified to date, investigations are continuing. In NSW in previous years, large outbreaks of this infection have been linked to swimming in contaminated pools. ${ }^{1}$ Other risk factors include contact with people and animals with the infection and drinking untreated water. To avoid contaminating swimming areas, people with diarrhoea should not enter swimming pools for at least one week after their symptoms have resolved.

Reports of hepatitis A increased in December (20 patients) and January (18 patients), mainly from metropolitan area health services. Four of these cases were linked to a restaurant where a food handler with hepatitis A had worked (see report below), and others cases have been linked to travel (including several people who travelled to Lebanon). People who have not been vaccinated for hepatitis $\mathrm{A}$, or have not had the infection, and who are planning to travel to areas where hepatitis A is endemic, which includes most non-industrialised countries, should be vaccinated against hepatitis $\mathrm{A}$.

Two confirmed cases of measles have been reported recently, both in overseas travellers. People planning to travel overseas should check their measles vaccination status, and everyone older than four years of age (and born after 1966) should have had two doses of measles vaccine before travelling.

\section{Reference}

1. Menzies R. EpiReview : Cryptosporidiosis in NSW, 1990-2000. N S W Public Health Bull 2002; 13(3): 54-57.

\section{A FOOD HANDLER DIAGNOSEDWITH HEPATITIS A}

On the 11 December, the Central Sydney Public Health Unit (CSPHU) was notified of a case of hepatitis A in a man. The CSPHU interviewed the man, who reported working as a chef in a restaurant in a large community club in Central Sydney. His duties comprised food handling and preparation, including raw salads and sandwiches, for one of the club's busy restaurants. He mentioned experiencing symptoms of a gastroenteritislike illness while at work. Although he reported to regularly wash his hands between preparation tasks, he did not wear gloves and had not received specific training in food handling. The period he was infectious while working was from 22 November to 9 December 2003.

Hepatitis A is typically transmitted from person-to-person by the faecal-oral route. Foodborne transmission commonly occurs when an infected person contaminates food during its preparation. ${ }^{1}$ Common source outbreaks caused by cooked and uncooked food contaminated by food handlers have occurred, ${ }^{2}$ such as the recent outbreak in Massachusetts where 46 people were infected. ${ }^{3}$ Postexposure prophylaxis with normal human immunoglobulin (NIGH) can prevent hepatitis A and is most effective when given early and within 14 days after exposure. ${ }^{4}$

The club estimated that 1,000 patrons may have dined at the restaurant in the period that the case was infectious. Patrons were alerted to the risk of possible hepatitis A transmission through contaminated food served at the restaurant by a media release, an 1800 hotline, and through club staff calling restaurant patrons for whom there were booking details on record. A clinic was set up to provide advice and offer NIGH to patrons who ate at the restaurant during the period that the case was infectious. At the clinic, a patrons' eligibility for NIGH was assessed, based on the date they dined at the restaurant, previous history of hepatitis A infection, and immunisation. Patrons without a completed immunisation history or prior infection with hepatitis A, who were within 14 days of exposure, were offered NIGH. All food handlers of the club were recommended to have NIGH.

Over five days, the clinic screened an estimated 1,166 people, 398 of whom did not qualify for NIGH and 768 of whom were provided with NIGH. The 1800 hotline was linked to an information line that operated from the clinic and received approximately 350 calls.

The incubation period for hepatitis A is typically 2-6 weeks. By 31 January, four possible secondary cases emerged. Only one of these people had received NIGH; however, the exposure of that person was outside the two-week period for the administration of NIGH to be effective. 


\section{References}

1. Chin J. Control of Communicable Diseases Manual: 17th edition. Washington DC: American Public Health Association, 2000; 238-243.

2. Massoudi MS, Bell BP, Paredes V, Insko J, Evans K, Shapiro CN. An outbreak of hepatitis A associated with an infected foodworker. Public Health Rep 1999; 114: 157-164.

3. Centers for Disease Control. Foodborne Transmission of Hepatitis A: Massachusetts, 2001. MMWR 2003; 52: 565-567.

4. Commonwealth Department of Health and Ageing. The Australian Immunisation Handbook, 8th edition. Canberra: Commonwealth of Australia, 2003. Available at www.immunise.health.gov.au/handbook.htm.

\section{ENTERIC DISEASE OUTBREAK CAUSED BY NOROVIRUS INFECTION ON A CRUISE SHIP}

Late in December 2003, the South Eastern Sydney Public Health Unit investigated a large outbreak of gastrointestinal illness on a passenger cruise ship.

Before docking in Sydney, the ship's doctor reported illness in up to 200 passengers, through the Public Health Unit's Cruise Ship Health Surveillance Program. Some specimens from ill passengers tested positive for Norovirus. Norovirus outbreaks are commonly reported in densely-populated settings, such as cruise ships, where person-to-person spread is the major mode of transmission.

In response to the outbreak, the ship's crew enhanced surveillance and medical care for possible cases, removed self-service food buffets, and increased the frequency of environmental cleaning regimes aboard the vessel. The outbreak subsequently subsided.

\section{SALMONELLOSIS OUTBREAK LINKEDTO A RESTAURANT}

On 26 November 2003, Western Sydney Public Health Unit (WSPHU) was notified of group of six people who became ill within 24-48 hours of dining at a restaurant on 21 November 2003. The following week, another group of 11 adults reported gastroenteritis within 24-72 hours of dining at the same restaurant on 23 November 2003. A further two cases who dined at the restaurant on 24 November were notified on 3 December 2003. One of these cases died. Salmonella typhimurium 170 was isolated from the stools of 13 cases, and in the blood from the case who died.

The WSPHU contacted a number of diners who had booked tables at the restaurant between 21-28 November, to establish if there was any evidence of continuing illness. A further two cases were identified in diners subsequent to 28 November.

Food inspectors visited the premises, as a result of the first report of illness. While the premises were found to be clean, food preparation practices indicated a potential for cross contamination. Corrective actions were discussed with the proprietor at the time.
On 5 December 2003, a teleconference was held between members of the NSW Department of Health Communicable Diseases Branch and the WSPHU at which it was decided that ongoing transmission could not be excluded and that the safety of diners could not be reasonably guaranteed if the restaurant continued to operate. On these grounds, it was concluded that the health of the public would be best protected if the restaurant were required to cease operating in the short-term, pending further assessment and management of any risks identified.

The restaurant was served a closure order on 5 December. Education on hygiene and food handling was first conducted on 27 November and again on 3 and 5 December. All perishable food was destroyed and the restaurant was thoroughly cleaned. On 8 December the order to close the restaurant was revoked and the restaurant was re-opened.

A case-control study was performed to assess the association between foods consumed and illness. Preliminary analysis suggested that a cooked rice dish may be responsible for illness. It is planned to report the results of the study and further details of the investigation in a future edition of the NSW Public Health Bulletin.

\section{MURRAY VALLEY ENCEPHALITIS VIRUS DETECTED IN A MENINDEE SENTINEL CHICKEN}

On 23 December 2003, routine testing of the sentinel chicken flock at Menindee, $100 \mathrm{kms}$ south of Broken Hill, detected Murray Valley Encephalitis (MVE) virus in a single chicken. No other chickens in the 15-strong flock tested positive. Two further tests have confirmed the infection, with no other birds becoming positive. The NSW Arbovirus Disease Monitoring Program has a number of sentinel flocks throughout the state. No other flocks reported any seroconversions. Similarly, flocks in Western Australia, the Northern Territory, and Victoria, reported no detections this season.

MVE virus is a virus affecting birds that is transmitted by mosquitoes. The last time MVE virus was detected in sentinel flocks in NSW was in 2001, ${ }^{1}$ when flocks in Menindee, Wanaaring, Bourke, and Macquarie Marshes tested positive. At that time, flocks in the Far West of the State converted first, with the virus apparently moving eastwards stopping at the Macquarie Marshes. Despite a number of opportunistic surveys of chicken flocks and other sentinels around the Dubbo, Moree, and Macquarie Marshes regions, no other detections were noted. However, while flocks along the Murray River did not detect any virus, an opportunistic serosurvey of domestic animals around the Menindee and Far West regions did show evidence of recent infection by the virus in animals as far south as Pooncarrie, $125 \mathrm{~km}$ south east of Menindee.

While the human population potentially at risk in the region is small, the Far West Area Health Service and the NSW Department of Health advised the public via media 
outlets of the risk of mosquito-borne disease around Menindee and Kinchega National Parks (particularly for campers in the advice to screen tents). Personal protective measures-including the use of mosquito screens around houses and tents and insect repellent and wearing light coloured clothing that covers the legs and arms-should be taken, especially by anglers and boaters, gardeners, and fruit pickers. Hospitals and general practitioners in Broken Hill, Mildura, and Adelaide, have been advised to maintain a high level of suspicion for MVE, when diagnosing encephalitic-type symptoms.

\section{Reference}

1. Communicable Diseases, NSW: March 2001. N S W Public Health Bull 2001; 12(3): 89-91.

\section{INVESTIGATION OF POSSIBLE SARS CASES}

On 14 January 2004, the Communicable Diseases Branch received a report that two flight attendants were admitted to a Sydney hospital with the diagnosis of possible SARS. They had become ill with influenza-like symptoms the previous morning, soon after arriving in Melbourne on a flight from China. The flight had departed from Guangzhou, where four sporadic cases of SARS were reported in December and January. The flight attendants had flown on to Sydney and presented to hospital the following day after their symptoms became worse.

The clinicians isolated the patients, used full personal protective equipment, and ensured that appropriate testing was performed for SARS and other possible pathogens. An expert panel of health professionals met by teleconference to help guide the management of the cases. Both patients were released from hospital three days later, when their improving clinical condition and negative laboratory tests effectively ruled out SARS. One flight attendant was subsequently shown to have influenza A and a specific diagnosis in the other remains unknown. Guidelines for the management of possible SARS cases can be found at the NSW Department of Health website at www.health.nsw.gov.au by clicking on the Quick Link to Infectious Diseases.

\section{RECOMMENDATIONS FROMTHE NSW TASKFORCE ON SARS}

Severe Acute Respiratory Syndrome (SARS) first appeared in southern China in late November 2002. By late February 2003, the disease began to spread around the world and on 12 March the World Health Organization (WHO) issued a global alert. Yet less than four months later, the epidemic was over. Central to the containment of this new disease was unprecedented international cooperation between public health, clinical, and laboratory teams. A new coronavirus was identified as the cause of SARS; and, no specific treatment has been identified. As of 15 October, 27 countries reported probable cases of SARS to the WHO.
A total of 8,098 probable infections, and 774 deaths, are estimated to have occurred worldwide, predominantly in certain provinces of China, and in Hong Kong, Taiwan, Singapore, Hanoi (Vietnam), and Toronto (Canada).

The SARS epidemic highlights the speed with which infections may spread around the world, and the need for a rapid and coordinated international public health response. With no reliable tests available for early diagnosis, and no specific treatment available, the most effective means of interrupting transmission was rapid identification and isolation of cases, follow up and quarantine of close contacts, and rigorous infection control practices.

In late April 2003, in response to the threat of severe acute respiratory syndrome, or SARS, the NSW Minister for Health announced the formation of the NSW Taskforce on SARS (TSARS). The TSARS first met on 1 May and comprised experts in the fields of public health, clinical medicine (intensive care, emergency medicine, mental health, and general practice), microbiology, infection control, ambulance, counter disaster, industrial relations, and communications. The TSARS provided a forum for discussion between health and other professionals about issues concerning SARS in NSW.

The TSARS was to advise the Chief Health Officer on:

- measures to be taken to prepare the NSW Health system for any outbreak of SARS in NSW;

- implementation of national disease control guidelines on SARS;

- communication strategies to inform health care workers and the general public of SARS-related issues;

- appropriate integration of clinical, public health, quarantine, and other services.

Five subcommittees were formed to address issues around infection control, clinical response and capacity, community health, clinical management, and staffing. Some of the key recommendations of TSARS were implemented during the time of the SARS crisis and others will require implementation in the near future.

In NSW, there were a total of 56 patients investigated who fitted the WHO definition of 'suspect' or 'probable' cases of SARS. All cases had travelled to a former SARS-affected area and all have completely recovered. Only one case has been confirmed by laboratory testing, and is in fact Australia's only confirmed case. This case was a foreign traveller infected in Hong Kong en route to Australia in late February, prior to the WHO issuing the global alert. The diagnosis was made retrospectively and a thorough investigation found no evidence of further spread.

Since the announcement by the WHO on 5 July that human-to-human transmission of SARS had been 
interrupted by January 2004, three further cases of SARS have been recorded globally: one each from Singapore and Taiwan-both thought to have been acquired from laboratory accidents - and a third in Southern China in late December, the source of which remains unclear. At the time of writing, there has been no secondary spread from these cases reported.

While at the time of writing (February 2004) the threat of SARS around the world appears low, it is important to remember that a single case is capable of igniting an outbreak. An environmental source has yet to be identified and it is unknown at this stage whether or not SARS is a seasonal disease. The risk of SARS re-emerging is therefore unknown and ongoing vigilance for the disease is needed.

The TSARS made 18 key recommendations. These are that:

1. NSW Health finalise an implementation strategy for the key recommendations of TSARS and that NSW Health devote the appropriate resources needed to carry out this strategy.

2. A strategy be developed for informing and educating the public in the event of a major communicable disease outbreak. Content will need to include general information about the unfolding epidemic, preventive messages, and advice on what to do if an individual suspects that they have the disease.

3. NSW Health establish improved systems for rapid communication of urgent advice to general practitioners and other medical practitioners. This may include systems using email, facsimile, print media, mobile phone networks, or rapid distribution of written materials through mail, or via services such as pathology couriers. The feasibility of utilising the existing mailing database of the NSW Medical Board needs to be explored.

4. All area health services report on proposed early management of possible SARS cases and their contacts, specific to their local circumstances, using a framework provided by NSW Health to ensure consistency of approach. Each area's plan needs to address the development of proposed fever clinics. This would entail nominating facilities and staff for the screening, triage, assessment, and isolation of cases. Consideration also needs to be given to 'staging facilities' for those that require observation but not acute hospital care.

5. All area health services identify and report on their strategies for management of SARS cases and their contacts in the community. This will include plans for patient transport, outpatient care, appropriate community supports for individuals in isolation and quarantine, and accommodation facilities for those unable to be managed in their homes. When a SARS case is released into home isolation, it is the responsibility of the treating clinicians (either hospital treating team or general practitioner) to formulate a comprehensive discharge plan.

6. NSW Health strengthens infection control practices in health care facilities by employing a "whole-ofsystem' approach. A greater focus on infection control at orientation sessions for new staff, provision of regular training and modelling on senior staff are some suggestions. A review of infection control policies and adherence to them is warranted, along with new systems to support senior health care facility management in improving infection control. In liaison with bodies representing general practitioners, a strategy needs to be developed to improve infection control in the general practitioner setting.

7. The NSW Department of Health Counter Disaster Unit designate a small number of suitable hospitals to manage suspected SARS patients in the event of an outbreak. Facilities are to be identified early, however, the final decision regarding their use would depend on the extent and location of any outbreak and must remain flexible.

8. Area health services ensure staff caring for possible SARS cases are screened for conditions that might increase their risk of serious disease, are well trained in infection control and the use of personal protective equipment, are aware of the risks involved, and are provided with adequate roster relief. Dedicated SARS teams were used in SARS-affected areas overseas, and are recommended in NSW. Additionally, if isolation of staff is required, they are to be provided with appropriate accommodation and arrangements made for the care of any dependents.

9. The NSW Department of Health Counter Disaster Unit review options for air transportation of possible SARS patients and identify barriers to safety, and strategies to overcome these.

10. NSW Health ensure the expert panel continues to be available to advise on management of SARS cases.

11. During any future outbreak of SARS, and in the interepidemic periods, that laboratories performing SARS testing in NSW ensure specimens sent to them for analysis have been triaged by the local public health unit. Laboratories will test specimens according to national guidelines and provide timely results of all tests relevant to the case to both the treating clinician and the public health unit.

12. NSW Department of Health Legal Branch identifies methods to streamline the process for making notifiable an emerging communicable disease, where initially only syndromic clinical criteria exist.

13. NSW Department of Health Legal Branch examine mechanisms for ensuring asymptomatic contacts of patients with SARS and other such communicable diseases can be placed in mandatory quarantine should it be deemed necessary by the Chief Health Officer. 
14. NSW Health establish a central cache of personal protective equipment with sufficient stock to protect health care workers in an outbreak.

15. The database of negative pressure and isolation facilities held by NSW Health Counter Disaster Unit be kept up-to-date and that a uniform standard to isolation and infection control infrastructure be used when designing or upgrading any future health care facilities.

16. In the event of a future SARS threat to Australia, a national border surveillance strategy be developed in light of existing evidence. This new strategy should be rapidly deployed. Additionally, if the Commonwealth perceives a future need for airport nurses to screen for SARS, their employment should be the responsibility of the Australian Quarantine Inspection Service.

17. NSW Health maintains a high level of vigilance for developments in relation to SARS and that national surveillance guidelines are disseminated to relevant groups for implementation in NSW.

18. NSW Health disseminate relevant reports of TSARS to key stakeholders.

\section{QUARTERLY REPORT: AUSTRALIAN CHILDHOOD IMMUNISATION REGISTER}

Table 1 presents the percentage of fully immunised children aged 12 months to less than 15 months in each area health service, reported by all service providers.

These data refer to five different cohorts of children whose age has been calculated 90 days before data extraction. The information contained in each of the reports has been extracted from the Australian Childhood Immunisation Register (ACIR) and may not reflect actual coverage due to under-reporting. Table 2 presents the percentage of fully immunised children identified as Aboriginal or Torres Strait Islander in New South Wales for the same cohort, reported by all service providers.

\section{TABLE 1}

PERCENTAGE OF FULLY IMMUNISED CHILDREN FOR FIVE SEPARATE COHORTS OF CHILDREN AGED 12 MONTHS TO LESS THAN 15 MONTHS BY AREA HEALTH SERVICE

\begin{tabular}{|c|c|c|c|c|c|}
\hline Area Health Service & 31 Dec 02 & 30 Mar 03 & 30 Jun 03 & 30 Sept 03 & 31 Dec 03 \\
\hline Central Coast & 93 & 93 & 92 & 93 & 95 \\
\hline Central Sydney & 90 & 91 & 90 & 90 & 89 \\
\hline Hunter & 94 & 94 & 95 & 93 & 94 \\
\hline Illawarra & 92 & 92 & 93 & 92 & 93 \\
\hline Northern Sydney & 91 & 90 & 91 & 91 & 90 \\
\hline South Eastern Sydney & 91 & 90 & 91 & 92 & 90 \\
\hline South Western Sydney & 92 & 91 & 90 & 91 & 90 \\
\hline Wentworth & 90 & 93 & 91 & 92 & 91 \\
\hline Western Sydney & 92 & 92 & 90 & 91 & 91 \\
\hline Far West & 89 & 93 & 88 & 91 & 93 \\
\hline Greater Murray & 93 & 92 & 94 & 93 & 93 \\
\hline Macquarie & 92 & 92 & 94 & 93 & 93 \\
\hline Mid North Coast & 90 & 90 & 89 & 90 & 91 \\
\hline Mid Western & 94 & 94 & 93 & 94 & 91 \\
\hline New England & 93 & 92 & 92 & 95 & 95 \\
\hline Northern Rivers & 85 & 85 & 84 & 85 & 84 \\
\hline Southern & 91 & 89 & 91 & 92 & 89 \\
\hline NSW & 91 & 91 & 91 & 91 & 91 \\
\hline Australia & 92 & 91 & 91 & 92 & 91 \\
\hline
\end{tabular}

\section{TABLE 2}

PERCENTAGE OF FULLY IMMUNISED CHILDREN IDENTIFIED AS ABORIGINAL OR TORRES STRAIT ISLANDER, FOR FIVE SEPARATE COHORTS AGED 12 MONTHS TO LESS THAN 15 MONTHS

\begin{tabular}{|lccccc|}
\hline & 31 Dec 02 & 31 & Mar 03 & 30 Jun 03 & 30 Sept 03 \\
\hline NSW & 86 & 86 & 84 & 88 \\
Australia & 84 & 86 & 84 & 87 & 82 \\
\hline
\end{tabular}




\section{QUARTERLY REPORT: HIV INFECTIONSTOTHE} END OF SEPTEMBER 2003

In 2002, there was a 15 per cent increase in the number of people reported to have newly-diagnosed HIV infection (392 cases) compared with 2001. This trend continued to the September quarter of 2003 (Table 3). In NSW, for the nine months to 30 September 2003, 322 people were reported to have been newly-diagnosed with HIV, which is an increase of 13 per cent and 24 per cent over the same periods of 2002 and 2001 respectively.

Of these 322 cases, 35 per cent $(n=114)$ infections were reported to have been newly-acquired (as opposed to newly-diagnosed). This compares with 32 per cent $(n=124)$ in 2002, 29 per cent $(n=98)$ in 2001,25 per cent $(n=87)$ in
2000 and 25 per cent $(n=94)$ in 1999. Newly-acquired HIV infection is defined as a new diagnosis of HIV infection with a reported negative test in the previous 12 months, or recent seroconversion illness, or laboratory evidence of new infection (including p24 antigen).

During the period January 1999 to September 2003, 90 per cent of newly-diagnosed HIV infections have been in men, and 96 per cent of newly-acquired HIV infections have been in men. Male-to-male sexual contact remains the predominant risk factor (65 per cent of all notifications, and 83 per cent of notifications of newlyacquired infection); the age group 30-39 years is the most affected and accounts for much of the rise in notifications since 2001. 


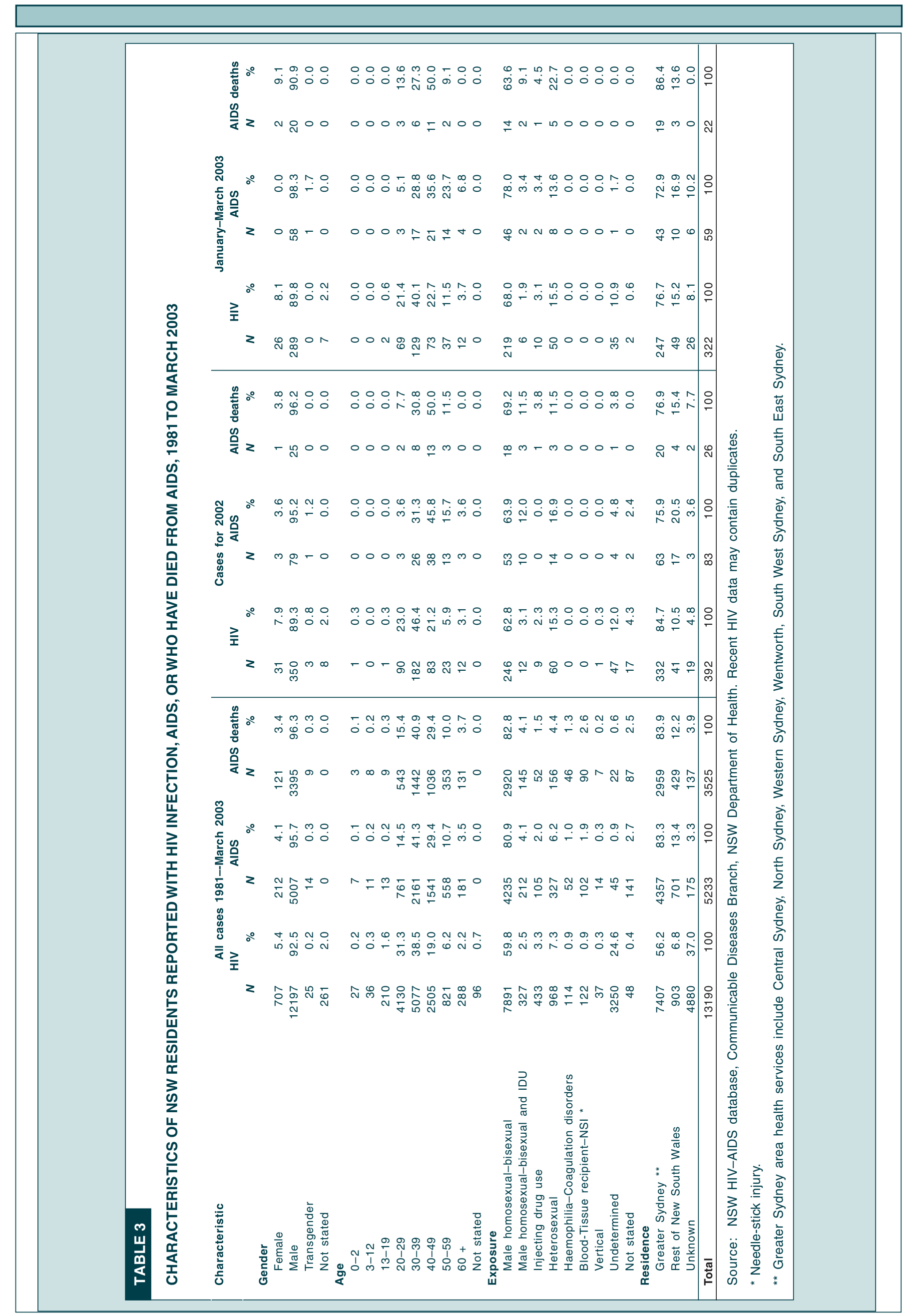




\section{FIGURE 1}

REPORTS OF SELECTED COMMUNICABLE DISEASES, NSW, JANUARY 1998 TO JANUARY 2004, BY MONTH OF ONSET

These are preliminary data: case counts for recent months may increase because of reporting delays. Laboratory-confirmed cases, except for measles, meningococcal disease and pertussis.

\begin{tabular}{|rc|}
\hline \multicolumn{2}{|c|}{ NSW population } \\
Male & $50 \%$ \\
$<5$ & $7 \%$ \\
$5-24$ & $28 \%$ \\
$25-64$ & $52 \%$ \\
$65+$ & $13 \%$ \\
Rural $^{*}$ & $42 \%$ \\
\hline
\end{tabular}
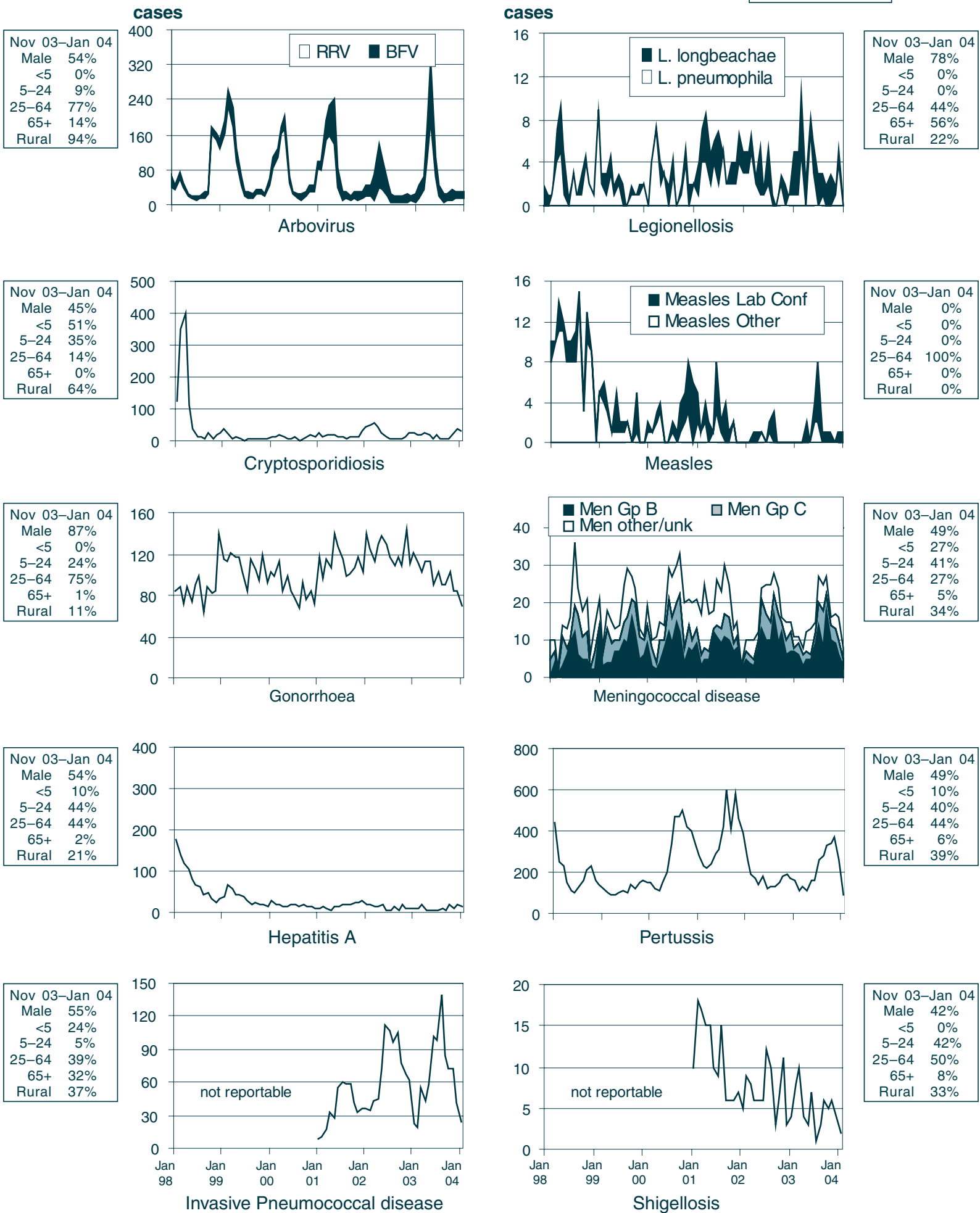


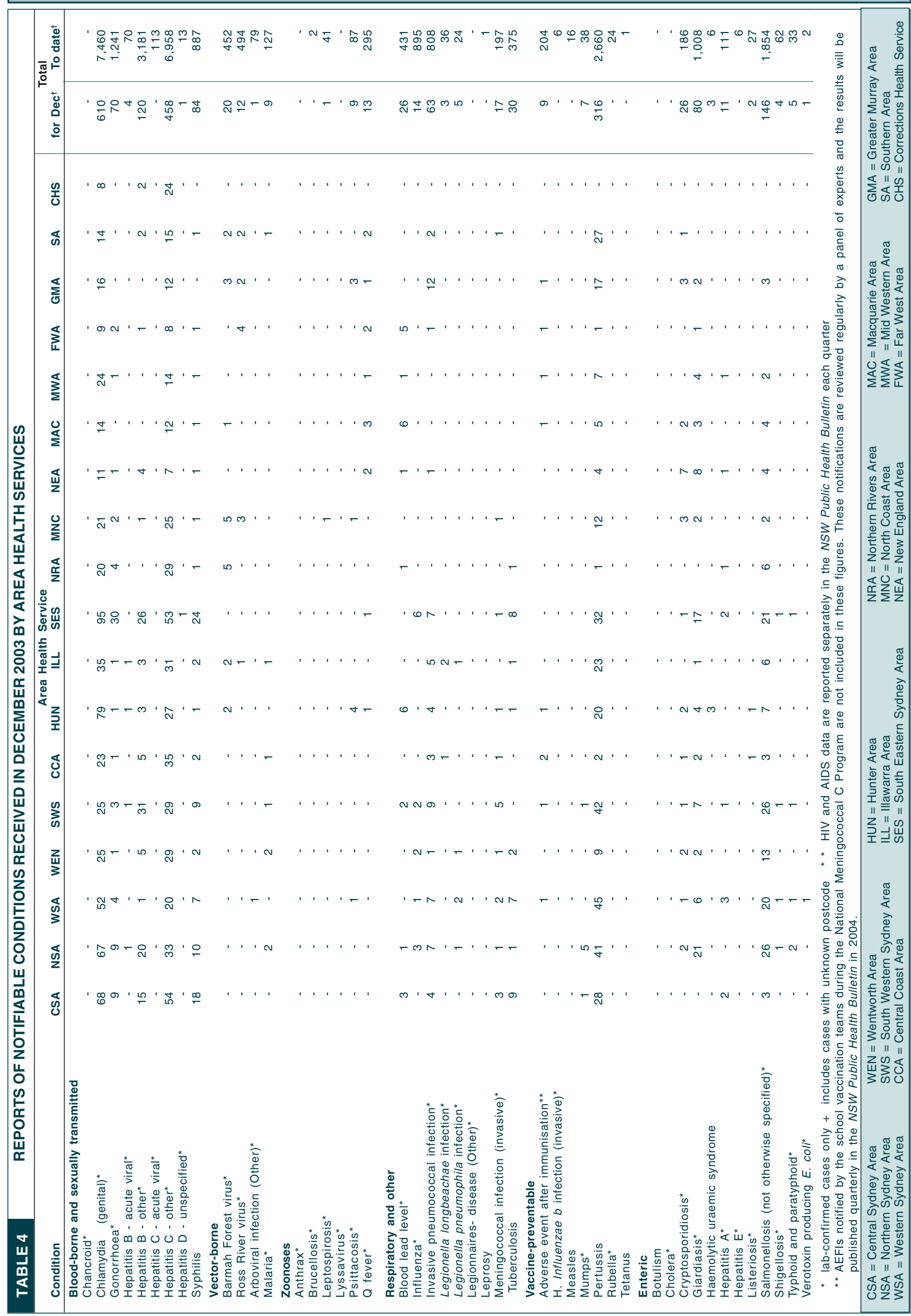




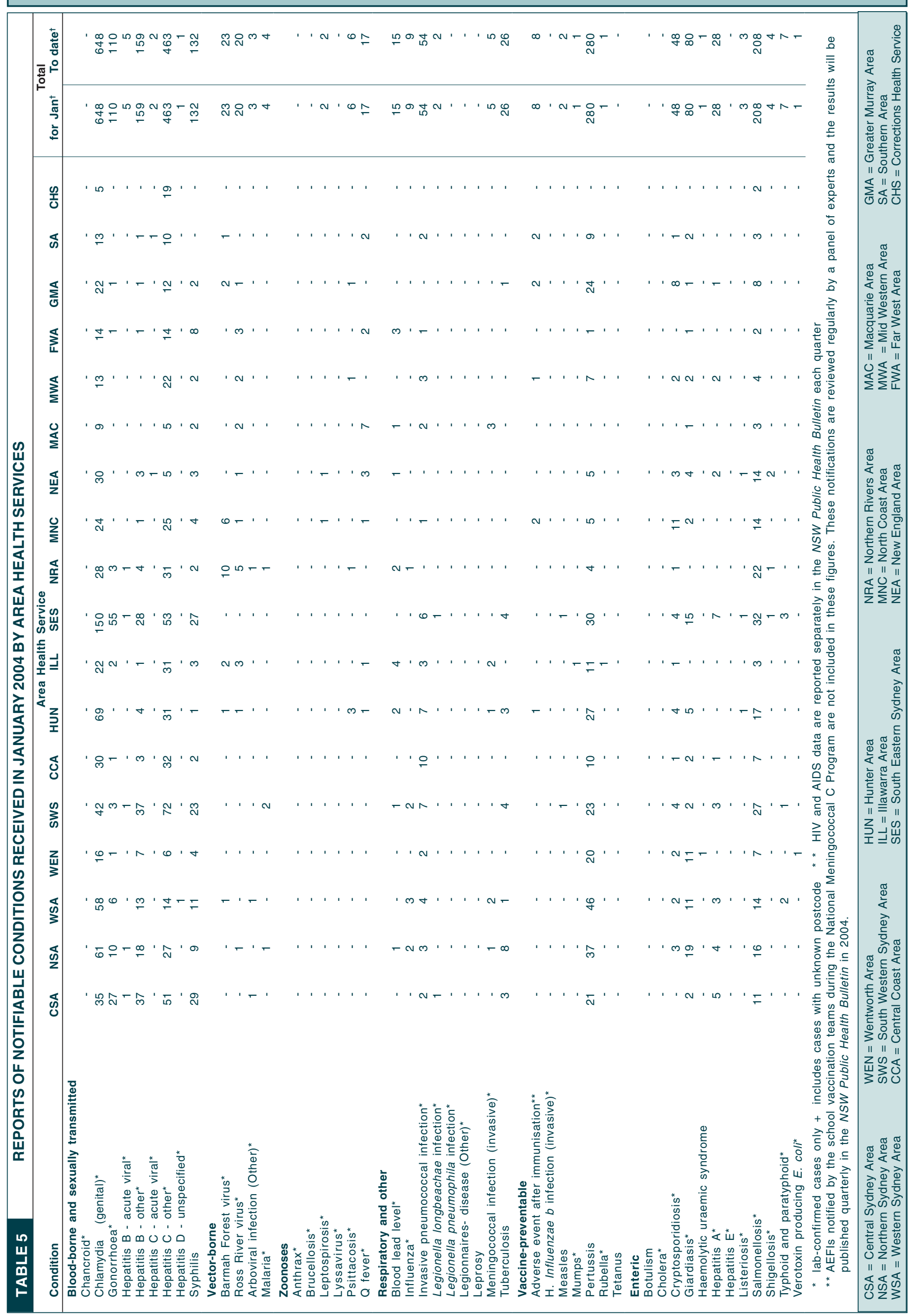

